\title{
INFLUENCE OF ANNEALING TEMPERATURE ON THE RECRYSTALLIZATION OF THE FERRITIC STAINLESS STEEL
}

\author{
Moura, A. N. ${ }^{1}$, ; Oliveira, T. R. ${ }^{2}$; Pontes, ${ }^{3}$; Itman Filho, A. ${ }^{1}$ \\ ${ }^{1}$ Materials and Metallurgical Departament of IFES, Vitória - ES/Brazil \\ ${ }^{2}$ Research Center of Aperam South America, Timoteo- MG/Brazil \\ 3 Professora Eloisa Mano Institute of Macromolecules, IMA/UFRJ, Rio de Janeiro- RJ/Brazil \\ *aria.ne@hotmail.com
}

Ferritic stainless steels are widely used in mechanical conformation by drawing. The objective of this paper is to study the annealing temperature effect on the recrystallization of the ferritic stainless steel AISI 430 containing niobium in order to improve its drawability. Samples of this steel was reduced $85 \%$ in thickness by cold rolled after annealed at $700^{\circ} \mathrm{C}$ to $1000^{\circ} \mathrm{C}$ for 25 seconds. The technique used for the characterization of hot rolled and annealed samples was the Electron Backscatter Diffraction (EBSD). The analysis was performed in a Scanning Electron Microscope $\left(\mathrm{LaB}_{6}\right)$. The step used to hot rolled and annealed samples was $2 \mu \mathrm{m}$ and $6 \mu \mathrm{m}$ respectively. The data processing was done in OIM (Orientation Imaging Micrograph) software. The results show the evolution of recrystallization with increasing temperature. The changes in the microstructure was observed by the image quality map and the increased of high angle boundary fraction by the grain boundary map. The complete recrystallization was obtained at $850^{\circ} \mathrm{C}$. The grain size increases when the annealing temperature increases. 